\title{
Reusable Electronics and Adaptable Communication as Implemented in the Odin Modular Robot
}

\author{
Ricardo Franco Mendoza Garcia, Andreas Lyder, David Johan Christensen and Kasper Stoy
}

\begin{abstract}
This paper describes the electronics and communication system of Odin, a novel heterogeneous modular robot made of links and joints. The electronics is divided into two printed circuit boards: a General board with reusable components and a Specific board with non-reusable components. While the General board is common to the design of every type of module, such as power, actuator, sensor and structure, the Specific board is unique to each type of module. The communication system, one of the most important reusable components of Odin, is based on local buses that can be extended by bridging electrical signals.

The implementations of actuator and power links show that splitting the electronics into General and Specific boards allows rapid development of different types of modules, and an analysis of performance indicates that the communication system is simple, fast and flexible.

As the electronic design reuses approx. 50\% of components between two different types of modules, we find it convenient for heterogeneous modular robots where production costs demand a small set of parts. In addition, as the features of the communication system are desirable in modular robots, we think it is suitable for such systems as well as useful for future research into flexible network topologies.
\end{abstract}

\section{INTRODUCTION}

Modular robots are robots built from many similar modules. Although single modules have limited uses, they are able to combine into more functional structures. A modular robot is homogeneous if all its modules are identical or heterogeneous if they are not [1].

The advantages of modular robots over robots made from a few special-purpose parts are three. First, their ability of assembling task-suitable structures makes modular robots more flexible. Second, their redundancy of modules makes them more robust. Third, their similarity between modules makes production of modular robots potentially cheaper [2].

At present, the promise of cheapness of modular robots is somewhat controversial [3]. Homogeneous modular robots with power, actuation and sensing capabilities in a single module are complex. Heterogeneous modular robots with those capabilities split into different types of modules are simpler, but their broader set of components makes production complex [4]. Thus, the designer of heterogeneous systems should consider reusing components across different types of modules to reduce the number of parts.

Ricardo Franco Mendoza Garcia, Andreas Lyder, David Johan Christensen and Kasper Stoy are with the Modular Robotics Lab, University of Southern Denmark, 5230 Odense M, Denmark ffranco, lyder, david, kaspers\}@mmmi.sdu.dk

Ricardo Franco Mendoza Garcia is also with the Escuela Universitaria de Ingenieria Mecanica, Universidad de Tarapaca, Arica, Chile

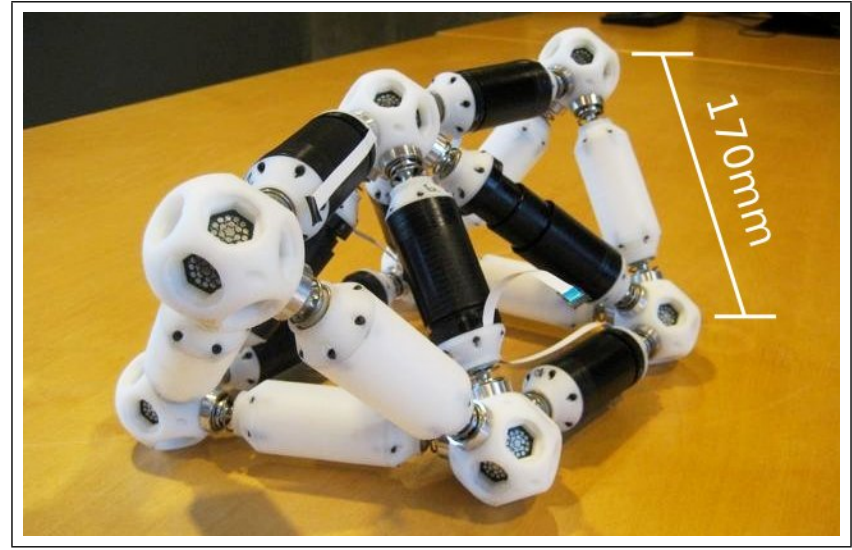

Fig. 1. The Odin heterogeneous modular robot. Odin is made of several types of links (rods) and one type of joint (spheres). Each type of link provides one specific functionality, such as power, actuation, sensing or structure, and the joints define the structure of the robot.

Odin is a modular robot made of several types of links (rods) and one type of joint (spheres) [5]. Each type of link provides one specific functionality, such as power, actuation, sensing or structure, and the joints define the structure of the robot [6], [7]. Because there are different types of links, and joints differ from links, Odin is a heterogeneous modular robot. Fig. 1 shows Odin.

Our approach for reusing components across different types of links is to split the electronics into two printed circuit boards, General and Specific. The General board hosts reusable components, and the Specific board hosts nonreusable components. In our system, reusable components are used in the design of every type of link, whilst nonreusable components are not. Microcontroller and communication system are examples of reusable components, and motor driver and battery charger are examples of nonreusable ones (not every link has a motor or a battery). As the General board hosts the entire set of reusable components required by any type of link, and the Specific board hosts the entire set of non-reusable components required by one type of link, we place one General and one Specific board in each link. Consequently, the General board is identical among different types of links, and the Specific board is unique to each type.

A different approach for reusing components is to embed all the electronics in a single printed circuit board (PCB). In this case, the PCB is over-dimensioned, and different regions are assigned to reusable and non-reusable components. Although this PCB hosts the entire set of non-reusable 


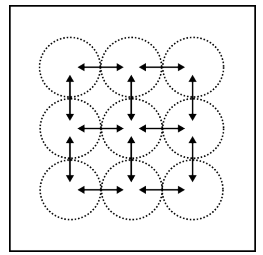

(a) Local Buses.

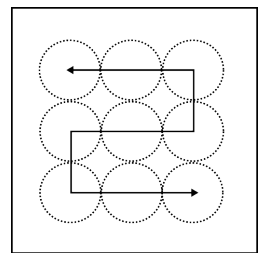

(b) Global Bus

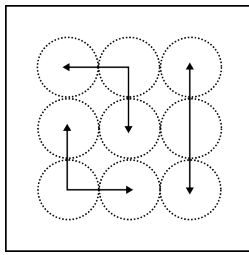

(c) Hybrid Buses.
Fig. 2. Three examples of network topologies provided by our communication system. Modules are represented by circles and buses by arrows. In (a), every module communicates only with adjacent neighbours using local buses. In (b), all the modules of the system communicate between each other through a global bus. Finally, in (c), several non-global channels, or hybrid buses, enable communication between non-adjacent modules. The global bus of (b) can be seen as a special case of hybrid bus.

components required by any type of link, only relevant electronics is mounted when implementing a specific type of link. In spite of potential low-costs, we do not follow this approach due to spatial constraints in our links, and because it demands the design of all types of links before any implementation.

One of the most important reusable components of Odin is the communication system. Communication is essential to modular robots. Local communication is used to figure out the topology of the robot and to coordinate tasks involving just local information [8], and global communication is needed for tasks that require time critical coordination between distant modules of the system [9]. Consequently, we implement both types of communications, local and global.

Our communication system provides a solution that is able to reconfigure the communication topology from small and local buses to long and more global buses, here called hybrid buses. We do not implement local and global communication by using separated media, again, because of spatial constraints in our links. Fig. 2 shows three examples of network topologies that our communication system can provide.

This paper describes the electronics and communication system of Odin. The implementations of actuator and power links demonstrate that split electronics allows for rapid development of different types of modules, and a performance analysis shows that the communication system is simple, fast and flexible. Notice that, in this paper, we evaluate the layout of the electronics, not its electrical performance.

We think that the electronics' layout is convenient for heterogeneous robots, because it keeps to some extent the homogeneity of the electronics by reusing approx. $50 \%$ of components between two different types of modules, and that the communication system is suitable for modular robots, because its features are desirable in such systems. In addition, we find the communication system useful for future research into the advantages of flexible network topologies.

\section{RELATED WORK}

Most modular robots are homogeneous [3], [10], [2], [5]. Heterogeneity complicates control algorithms and impacts scale economies [4]. Nevertheless, heterogeneous modular robots are more capable than homogeneous counterparts [3],
[4], [6]. For example, while heterogeneous robots can use wheel modules for fast locomotion and gripper modules for accurate manipulation [6], homogeneous robots require either a larger amount of modules or highly integrated hardware to do the same. This fact makes homogeneity expensive when addressing performance [4], [6]. In addition, while homogeneous modular robots appeal to spatial and weight constrained tasks (e.g., space missions) [2], heterogeneous modular robots expand the range of tasks compared to that of conventional robots.

The range of heterogeneous modular robots extends from homogeneous systems enhanced with external sensors [11] to systems like Odin [4], which have completely different types of modules [6]. To the best of our knowledge, Odin is the second modular robot following this radical approach after CEBOT [12], the first modular robot ever made. In CEBOT, the only reusable components between different types of modules were processing power and communication system.

For understanding the electronic requirements of modular robots, we look into technical details of current implementations. As said before, most modular robots are homogeneous, and, as expected, their electronics is complex. One module of existing systems has several microcontrollers operating power, actuation, communication and self-reconfiguration. For instance, the amount of microcontrollers per module in M-TRAN II is four [13], in ATRON I is also four [14] and in SUPERBOT is two [15]. Notice, however, that few functions are assigned to each microcontroller. For instance, the simpler modules of POLYBOT embed only one microcontroller [16]. As the links of Odin aim to provide only one function, we base our design on a single microcontroller.

We also look into communication approaches. Apparently, there is no common agreement about local or global communication as the ultimate choice for modular robots; both exist in current implementations. For instance, communication in POLYBOT is global [16], in M-TRAN II is local and global [13], in ATRON is local [14] and in SUPERBOT is local [15]. Nevertheless, communication topology does influence control strategies, as shown by POLYBOT's centralized gait tables [16], MTRAN's centralized central pattern generators [17] and SUPERBOT's distributed digital hormone [18]. It seems that global communication is convenient for centralized control, and local communication is convenient for distributed control [9], [3]. As our interest is to explore control strategies based on centralized and distributed aspects, Odin has both communications. In addition, Odin introduces the concept of hybrid buses (see Fig. 2) and uses a common medium and hardware for the whole communication system [19].

\section{MEChANICAL FRAMEWORK}

We developed the electronics and communication system of Odin constrained by a mechanical framework. Odin is a heterogeneous modular lattice-type robot made of links and joints. Links are cylinders of $35 \mathrm{~mm}$ diameter and $120 \mathrm{~mm}$ length, which have spring-loaded connectors at each extreme to hook up joints. Joints are spheres of $50 \mathrm{~mm}$ diameter, 


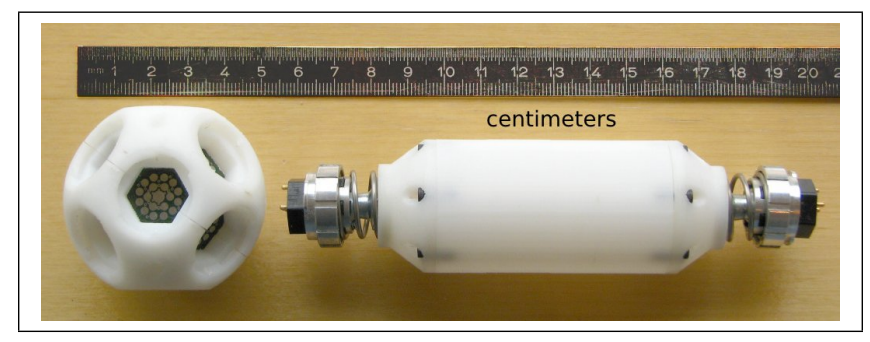

Fig. 3. Link (rod) and joint (sphere): the two basic types of modules of Odin. Links have spring-loaded connectors at each extreme to hook up joints, and joints have 12 sockets to host links. This flexible connectorsocket mechanism allows the system to perform movements by deforming its lattice. Links are cylinders of $35 \mathrm{~mm}$ diameter and $120 \mathrm{~mm}$ length, and joints are spheres of $50 \mathrm{~mm}$ diameter.

which have sockets to host links [5]. Depending on the amount and position of these sockets, joints arrange links into specific lattices. Currently, 12 sockets in the joints create structures complying with the cubic closed packing lattice (CCP) [20]. Besides passing power and communication lines, the flexible connector-socket mechanism allows the system to perform movements by deforming its lattice [7]. Fig. 3 shows a link and a joint of Odin.

\section{ELECTRONICS' LAYOUT}

\section{A. Requirements}

For simplicity at the modules' level, we wanted each type of link to provide only one function: power, actuation, sensing or structure. For exploring centralized and distributed aspects of control, we wanted local and global communication. For low production costs, we wanted to reuse as many components as possible between different types of links. Finally, as links aimed to provide only one function, we wanted them to embed a single microcontroller each.

\section{B. Design}

1) Power distribution: As power sources (e.g., batteries) were expected in only one type of link, we designed a parallel-powered system or, in our case, a system with powerforwarding across the bodies of links and joints. In this way, a single power source could energize, at least in theory, all the links connected to the system. In practice, energy and power densities would limit the amount of links energized by a single power source.

2) Communication system: As links had little space available for electronics, we decided to have local communication with the possibility of extending the scope of local buses by bridging electrical signals. In this way, we could eventually provide global communication. Local buses were placed outside the links, inside the joints. Section V details this communication scheme.

3) General and Specific PCBs: As we expected to share some hardware requirements between different types of links, we split the electronics into two PCBs: a General board with reusable components and a Specific board with nonreusable ones. While reusable components were foreseen for the design of every type of link, non-reusable components

\begin{tabular}{|l|l|}
\hline Component & Purpose \\
\hline Microcontroller $(1 \mathrm{x})$ & control of link's function and communication. \\
\hline Transceivers $(1 \mathrm{x})(1 \mathrm{x})$ & $\begin{array}{l}\text { conditioning of communication signals at } \\
\text { each end of the link. }\end{array}$ \\
\hline $\begin{array}{l}\text { Low-level } \\
\text { Volt. Regulator }(1 \mathrm{x})\end{array}$ & $\begin{array}{l}\text { power for microcontroller and low-level elec- } \\
\text { tronics. }\end{array}$ \\
\hline Connectors $(3 \mathrm{x})(2 \mathrm{x})$ & $\begin{array}{l}\text { forwarding of power, communication and mi- } \\
\text { crocontroller lines between boards and from } \\
\text { boards to link's exterior. }\end{array}$ \\
\hline Flat Cables $(2 \mathrm{x})$ & $\begin{array}{l}\text { forwarding of power, communication and mi- } \\
\text { crocontroller lines between boards and from } \\
\text { boards to link's exterior. }\end{array}$ \\
\hline
\end{tabular}

TABLE I

COMPONENTS FOUND IN THE DESIGN OF EVERY TYPE OF LINK OF ODIN.

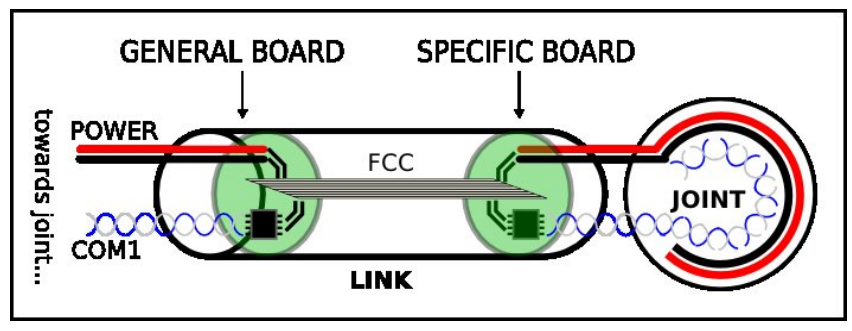

Fig. 4. Electronics' layout of Odin. The General board hosts reusable components and is common to the design of every type of link. The Specific board hosts non-reusable components (plus a few reusable ones) and is unique to each type of link. Each board is placed at opposite ends of the link, and they interconnect by a flat cable (FCC) passing power, communication and microcontroller lines. Power and communication lines are furthermore sent to the joints. For the sake of simplicity, this figure does not include all reusable components.

were allowed to be unique to each type of link. Table I summarizes the set of reusable components of Odin.

Due to the communication topology, each board was placed at opposite ends of the links. Thus, although we embedded most of the reusable components in the General board, we also needed a few of them in the Specific board. These components, indicated with red quantities in Table I, included a communication transceiver for close access to the local bus at the Specific board's end. A flat cable (FCC) was then assigned to pass power, communication and microcontroller lines between boards. Fig. 4 summarizes the electronics' layout of Odin.

\section{Implementation}

1) Power distribution: We decided to propagate a minimum voltage of $9 \mathrm{~V}$ and dimensioned connectors, contacts and wires to handle a maximum current of $2 \mathrm{~A}$. We also set the maximum power consumed by any type of link to $5 \mathrm{~W}$, so links could forward power to 2 other links (worse case). In addition, we used 8 lines of FCC for power-forwarding: 4 for $9 \mathrm{~V}$ and 4 for GND.

2) Communication System: In the current iteration of Odin, for extending the reach of the local buses, we repeated the electrical signals at the microcontroller side of the communication (UART bridging). Section V details the implementation of this communication scheme. 


\begin{tabular}{|l|l|}
\hline Microcontroller Lines & Purpose on the Specific board \\
\hline UART port $(3 \mathrm{x})$ & control of communication transceiver. \\
\hline $\begin{array}{l}\text { PWM channels }(4 \mathrm{x}) \\
\text { or SPI port }(4 \mathrm{x})\end{array}$ & $\begin{array}{l}\text { control of motors, DACs, or LEDs. } \\
\text { control of SPI integrated devices. } \\
\text { or Digital I/O }(4 \mathrm{x})\end{array}$ \\
\hline $\begin{array}{l}\text { ADC channels }(4 \mathrm{x}) \\
\text { general purpose digital inputs and outputs. }\end{array}$ \\
$\begin{array}{l}\text { acquisition of signals from analog sensors. } \\
\text { general purpose digital inputs and outputs. }\end{array}$ \\
\hline
\end{tabular}

TABLE II

Microcontroller LINES BETWEEN GENERAL AND SPECIFIC BOARDS.

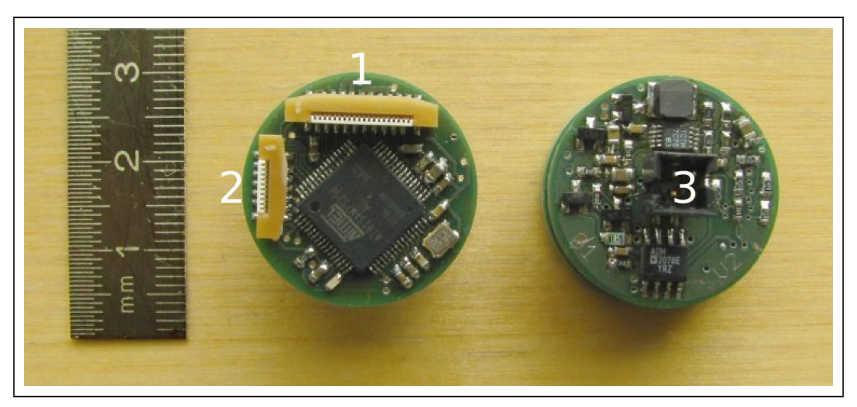

Fig. 5. Front (left) and back (right) of the General board of Odin. This board embeds: one 32-bit 50MHz AT91SAM7S256 microcontroller, one $3.3 \mathrm{~V}$ voltage regulator, one communication transceiver and 3 connectors $(1,2,3)$. (1) sends power, communication and microcontroller lines to the Specific board, (2) sends JTAG lines to the link's exterior and (3) forwards power and communication lines to the joints. The General board is a 4-layers PCB of $25 \mathrm{~mm}$ diameter.

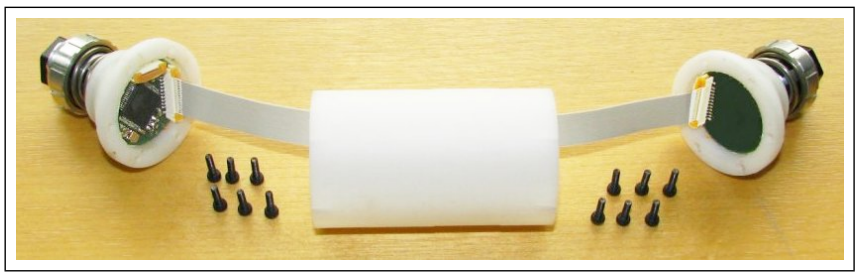

Fig. 6. Electronics' layout of Odin. General (left) and Specific (right) boards are interconnected by a 20-lines flat cable. The lines' purposes are: 8 for power-forwarding, 1 for $3.3 \mathrm{~V}$ and 11 for microcontroller signals (UART, PWM, SPI, ADC and digital I/O). Although the Specific board in the picture is only a mock-up, it shows that future implementations require a few reusable components ( 2 connectors and 1 transceiver).

3) General and Specific PCBs: Due to low power requirements and plenty of peripherals in a small footprint, we chose the 32-bit 50MHz AT91SAM7S256 microcontroller from Atmel. We then used 12 lines of FCC to propagate microcontroller signals (11 lines) and a low-level voltage of $3.3 \mathrm{~V}$ (1 line) from General to Specific board. Consequently, the final count of FCC's lines was 20. Table II summarizes the purposes of the 11 microcontroller signals, and Fig. 5 shows the implementation of the General board.

As the Specific board was decided to be unique to each type of link, its heterogeneous implementations were delayed until subsequent stages. Despite that, Fig. 6 shows the implementation of the electronics' layout of Odin by using a mock-up of such board.

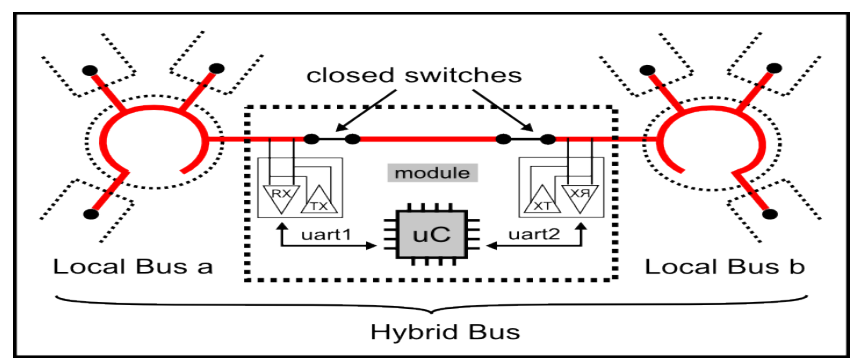

Fig. 7. RS485 bridging of two local buses. Buses are represented by a single line, in spite of they are conformed by two wires. In RS485 bridging, links attach an internal RS485 bus to the local buses, what results in a more global bus called hybrid bus. In UART bridging, there is not internal RS485 bus, and the UART ports of the microcontroller are bridged instead.

\section{Communication System}

\section{A. Requirements}

As mentioned in the requirements of Sec. IV, we wanted local and global communication. Considering typical demands of modular robots, we also wanted high transfer rates, high scalability, low power consumption and little spatial requirements.

\section{B. Design}

1) Local Buses: Due to the difficulties we experienced with infrared communication in ATRON [21], we decided on RS485 communication for Odin. Despite the varying nature of the communication topology, the placement of local buses inside joints allowed for proper allocation of termination impedances. This approach, however, required links to include two transceivers for accessing two local buses and the connector-socket mechanism (described in Sec. III) to forward communication signals [7].

2) Hybrid and Global Buses: To obtain local and global communication, we decided to extend the reach of local buses. This approach also allowed to create hybrid buses as presented in Fig. 2. Nevertheless, there were two alternatives for such extension: merging local buses at the transceivers side (RS485 bridging) or repeating electrical signals at the microcontroller side (UART bridging).

At this point, we were not decided about which bridging approach to follow. For RS485 bridging, links required an internal RS485 bus with switches to join together the two local buses being accessed. For UART bridging, links required a repeater circuitry between the UART lines going from the microcontroller to the transceivers. Fig. 7 summarizes the communication scheme under RS485 bridging.

3) Termination Impedance: Under RS485 bridging, two $120 \Omega$ terminations per local bus could overload transceivers if merging two or more such buses [22]. Despite the final decision about bridging approach, we decided on AC terminations instead[23] and placed them at each end of the local buses inside the joints.

\section{Implementation}

1) Local Buses: The local buses were implemented as a continuous route between 12 PCBs embedded inside the 


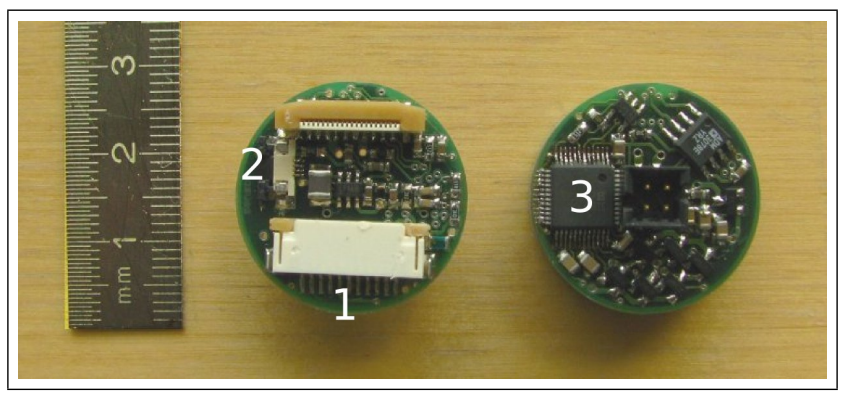

Fig. 8. Front (left) and back (right) of the Specific board implemented for the actuator links, also called Linear Actuator board. Besides a few reusable components, this board is equipped with a motor driver (3) and two interfacing connectors: (1) for a motor and (2) for a linear displacement sensor. The Specific board is a 4-layers PCB of $25 \mathrm{~mm}$ diameter.

joints. These PCBs were put together in a polyhedron arrangement, which matched each face with a socket of the joints [7]. In addition, we used transceivers of $1 / 8$ of load to allow hybrid buses as large as 256 links under RS485 bridging.

2) Hybrid and Global Buses: We implemented both bridging approaches in different iterations of Odin. Under RS485 bridging, we tried to follow the RS485 wiring guidelines [24], and so we used analog switches with low ON resistance to minimize reflections. Under UART bridging, we simply used a feature of our microcontroller to bridge the UART ports. Sec. VII details the advantages/disadvantages of both bridging approaches.

3) Termination Impedance: We placed two components on each AC termination: one resistor, $R_{T}$, and one capacitor, $C_{T}$. While $R_{T}$ matched the characteristic impedance of a

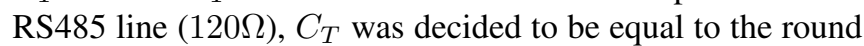
trip delay of the cable divided by $R_{T}$ [23]. The round trip delay is defined as twice the time required for a signal to travel until the end of a line. Thus, $C_{T}$ was calculated as:

$$
C_{T}=2 \frac{1}{120} \frac{l_{\max }}{0.66 c}
$$

where $0.66 c$ represented the typical propagation velocity of a twisted pair cable and $l_{\max }$ represented the maximum expected length of the hybrid buses. Based on a previous estimation of $l_{\max }$ for Odin [19], the value of $C_{T}$ was calculated as $1 n F$.

\section{RESUlts}

\section{A. Implementation of Links}

1) Actuator Links: These links were designed to perform controlled linear extension/contraction by using a telescopic mechanism, a brushless DC motor (BLDC) and a linear displacement sensor. Besides the reusable components described in Section IV, the Specific board of these links, also called Linear Actuator board, was equipped with a motor driver and 2 connectors for interfacing motor and sensor. Fig. 8 shows the Linear Actuator board, and Fig. 9 shows the Actuator link finally assembled.

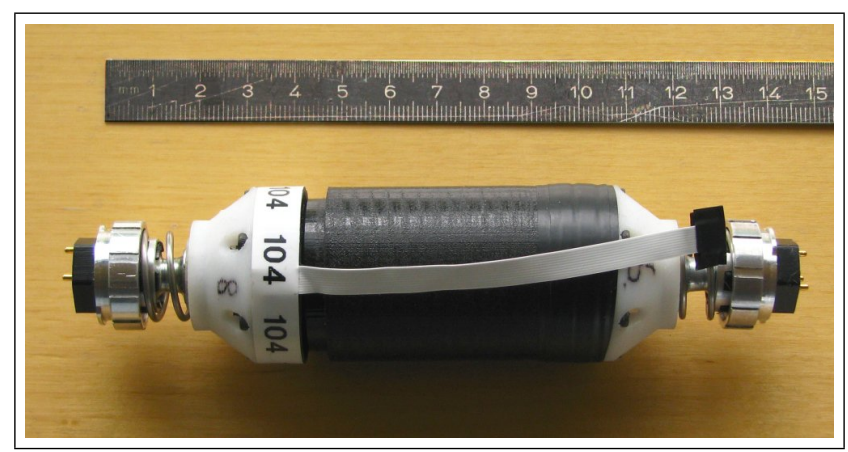

Fig. 9. Linear actuator link of Odin. This type of link performs controlled linear extension/contraction by using a telescopic mechanism, a brushless DC motor and a linear displacement sensor.

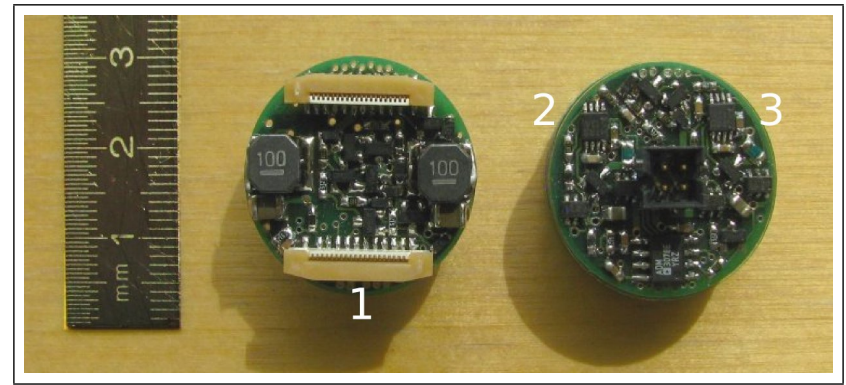

Fig. 10. Front (left) and back (right) of the Specific board implemented for the power links, also called Power board. Besides a few reusable components, this board is equipped with 2 step-down voltage regulators $(2,3)$ and 1 connector (1) for interfacing the power coming from a $3 \mathrm{~S} \mathrm{Li}$ Poly battery pack. The Specific board is a 4-layers PCB of $25 \mathrm{~mm}$ diameter.

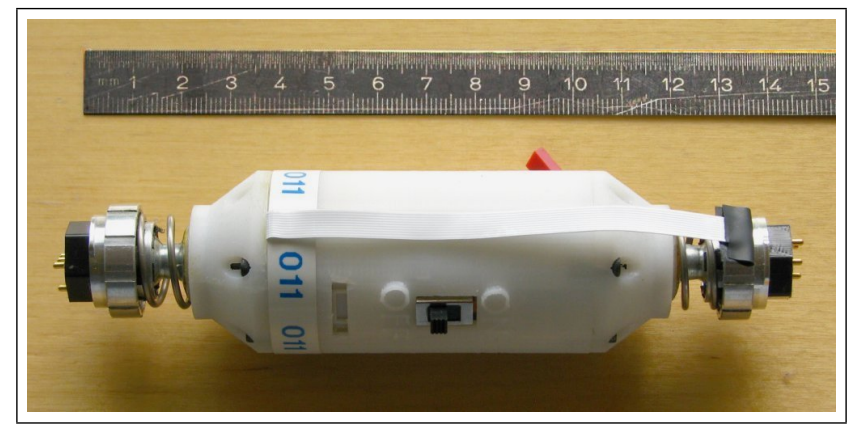

Fig. 11. Power link of Odin. This type of link provides (2x) 9V/2A to the power bus of Odin from a $3 \mathrm{~S}$ Li-Poly battery pack.

2) Power Links: These links were designed to provide (2x) $9 \mathrm{~V} / 2 \mathrm{~A}$ to the power bus of Odin from a $3 \mathrm{~S}$ Li-Poly battery pack. Besides the reusable components described in Section IV, the Specific board of these links, also called Power board, was equipped with 2 step-down voltage regulators and 1 connector for interfacing the power coming from the batteries. Fig. 10 shows the Power board, and Fig. 11 shows the Power link finally assembled.

3) Development Time: We spent roughly 3 months with the General board, 3 months with the Power board and 3 months with the Linear Actuator board, and we developed the mechanics in parallel to the electronics. 


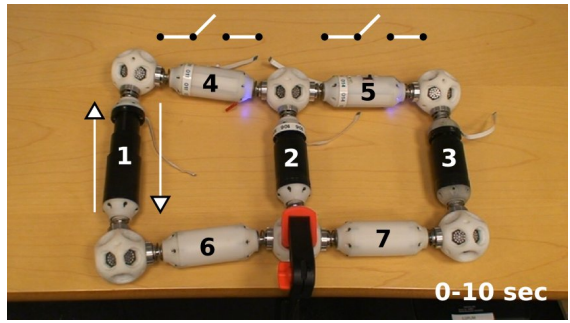

(a) One actuator moving.

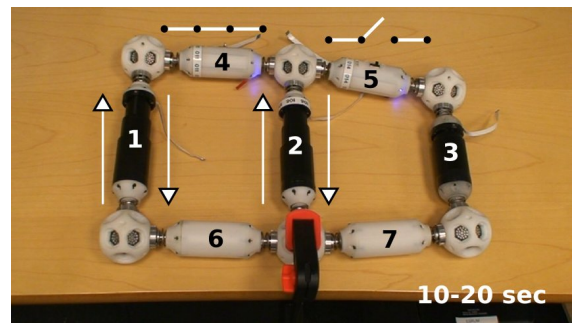

(b) Two actuators moving synchronously.

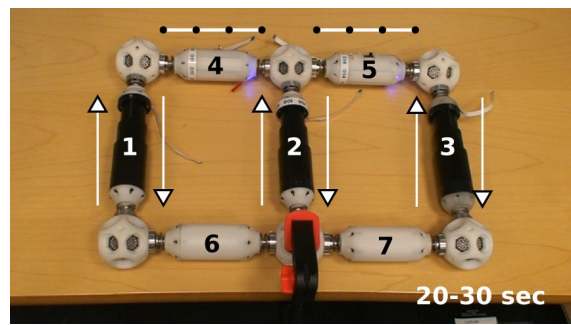

(c) Three actuators moving synchronously.

Fig. 12. Proof-of-concept experiment to show links and communication system running. All links begin execution with internal bridges open. In addition, all actuators $(1,2,3)$ are prepared to execute extend/contract orders, but only actuator (1) sends such orders to itself and to its neighbours. In (a), actuator (1) extend/contract alone at certain frequency. In (b), power link (4) closes its internal bridge, and actuators $(1,2)$ extend/contract synchronously. In (c), power link (5) closes its internal bridge, and all actuators extend/contract synchronously.

4) Percentage of Reused Electronics: Considering that we added less additional components to the Specific boards than the amount of components shown in Table I, the percentage of reused components between these two different types of links was greater than $50 \%$.

\section{B. Communication Performance}

1) RS485 bridging: For evaluating communication performance, we used a rule of thumb of transmission lines with AC terminations. This rule says that the time constant, $\tau=R_{T} C_{T}$, should be less or equal to $10 \%$ of the bit width [23]. Thus, the maximum transfer rate was determined as:

$$
t r_{\max }=\frac{1}{10} \frac{1}{120 C_{T}}=\frac{0.66 c}{20 l_{\max }} \text { bps }=\frac{9.9}{l_{\max }} \text { Mbps }
$$

for any system implementing RS485 bridging. Likewise, the maximum transfer rate for Odin was determined as:

$$
t r_{\text {max_odin }}=\frac{1}{10} \frac{1}{120 * 10^{-9}} \approx 833 \text { Kbps }
$$

2) UART bridging: As no physical bridging between RS485 buses was present, UART bridging promised higher transfer rates than RS485 bridging. In this case, the maximum transfer rate was only constrained by the maximum transfer rates of the local buses and the delay of the repeater circuitry.

As the repeater circuitry was meant to be independent of the microcontroller, we ignored hardware-related delays in the propagation times. Considering thus only the small length of the local buses inside the joints, Eqn. 2 suggested a maximum transfer rate near to the full capacity of existing transceivers (10Mbps).

\section{Experiment}

Fig. 12 captures three snapshots of a proof-of-concept experiment showing links and communication system running. The assembly consisted of three actuator $(1,2,3)$, two power $(4,5)$ and two passive links $(6,7)$. Passive links do not have internal electronics.

All links begun execution with internal bridges open. In addition, all actuators $(1,2,3)$ were prepared to execute extend/contract orders, but only actuator (1) was sending such orders to itself and to its neighbours. The role of power links $(4,5)$ was to establish extended communication buses. Consequently, power links $(4,5)$ closed their internal bridges after 10 and 20 seconds, respectively.

The behaviour of the assembly was as follow: at first, actuator (1) extended/contracted alone, after 10 seconds, actuators $(1,2)$ extended/contracted synchronously and, after 20 seconds, actuators $(1,2,3)$ extended/contracted synchronously.

\section{DISCUSSION}

The Odin robot, as reviewed, represents less than 1-year of group work. This fact demonstrates that split electronics accelerates the development of new modules by: (1) providing a General board with electronics (and software) ready-to-use and (2) predetermining an interface for the new electronics in the Specific board. Although (2) somehow limits the capabilities of the Specific board, it suits the vision of mono-functional links.

Even though the General board allows to reuse at least $50 \%$ of electronics components between two different types of links, when more types of links are built, this percentage can decrease. However, the percentage refers to types and not amounts of components. For instance, 5 power, 5 actuator and 5 sensor links may require 5 chargers, 5 motors and 5 distance sensors, but also 15 microcontrollers. Reuse of the so called "non-reusable" components at the Specific board can be furthermore taken to higher degrees. For example, the same electronics for driving a motor may be used in linear, rotational and hinge actuators.

After implementing both bridging approaches, we realize that UART bridging simplifies assembly by excluding the internal RS485 bus and that RS485 bridging demands less amount of components by excluding repeater circuitry. Nevertheless, both approaches promise high transfer rates, demand a few electronics components and rely on a robust physical layer. What is more, AC terminations satisfy power saving requirements too [23].

The experiment shows how links can be used as communication bridges to extend the reach of local buses. In Fig. 12.c, power links $(4,5)$ establish a global bus, which allows for direct broadcasting of messages from actuator (1) 
to actuators (2,3). With many modules arranged in a linear formation (i.e., snake), the creation of a global bus could improve the transmission times compared to those obtained from using only local buses [9].

The flexibility of hybrid buses makes them especially useful when the tasks of the system are split in roles [25] [26]. In that case, every role (e.g., leg, arm, or spine) can be coordinated by a hybrid bus, which has a highly optimized topology for the duty on hand. As the task or role changes, the communication topology can be again optimized.

\section{CONCLUSIONS}

This paper described the electronics and communication system of Odin. We shown how the split of electronics accelerated the implementation of actuator and power links, and that, despite we were implementing a heterogeneous system, the electronics' layout provided certain degree of homogeneity to our links. We thus believe that our design is convenient for heterogeneous modular robots where production costs demand a small set of parts and spatial requirements are tight.

We also shown that the communication system demanded a small amount of components and was built over a robust physical layer. In addition, our performance analysis indicated that the communication system was also able to achieve high transfer rates. We thus conclude that such communication approach is suitable for modular robots, because all its features are desirable in these systems. In addition, we believe that a flexible communication topology appeal to systems implementing role-based control, because it can optimize connectivity between any group of modules.

\section{ACKNOWLEDGMENT}

This work was partially funded by Intel Research, Pittsburgh, and the Chilean Ministry of Education through the project Mecesup UTA0304. Special thanks to Mirko Bordignon for his fruitful comments on this paper.

\section{REFERENCES}

[1] M. Yim, Y. Zhang, and D. Duff, "Modular robots," IEEE Spectrum, vol. 39, no. 2, pp. 30-34, February 2002.

[2] M. Yim, W.-M. Shen, B. Salemi, D. Rus, M. Moll, H. Lipson, E. Klavins, and G. S. Chirikjian, "Modular self-reconfigurable robot systems: Challenges and opportunities for the future," IEEE Robotics and Automation Magazine, pp. 2-11, March 2007.

[3] K. Kotay, "Self-reconfiguring robots: designs, algorithms, and applications," Ph.D. dissertation, Dartmouth College, 2003.

[4] R. C. Fitch, "Heterogeneous self-reconfiguring robotics," Ph.D. dissertation, Department of Computer Science, Dartmouth College, September 2004.

[5] A. Lyder, "Deformable modular robots: A new direction in modular robotics," Master's thesis, The Maersk Mc-Kinney Moller Institute, University of Southern Denmark, Odense, Denmark, 2007.

[6] K. Stoy, A. Lyder, R. F. M. Garcia, and D. J. Christensen, "Hierarchical robots," in IROS Workshop on Self-Reconfigurable Robots/Systems and Applications, San Diego CA, 2007.

[7] A. Lyder, R. F. M. Garcia, and K. Stoy, "Mechanical design of odin, an extendable heterogeneous deformable modular robot," in Proceedings of the IEEE International Conference on Intelligent Robots and Systems (IROS2008), 2008.

[8] R. Nagpal, "Organizing a global coordinate system from local information on an amorphous computer," AI Memo, no. 1666, August 1999.
[9] E. Yoshida, T. Arai, M. Yamamoto, J. Ota, and D. Kurabayashi, "Evaluating the efficiency of local and global communication in distributed mobile robotic systems," in Proc. IEEE International Conference on Intelligent Robots and Systems (IROS'96), Osaka, Japan, November 1996, pp. 1661-1666.

[10] E. H. Ostergaard, "Distributed control of the ATRON selfreconfigurable robot," Ph.D. dissertation, The Maersk Mc-Kinney Moller Institute for Production Technology, University of Southern Denmark, November 2004.

[11] K. Stoy, W.-M. Shen, and P. Will, "On the use of sensors in selfreconfigurable robots," in 7th international conference on simulation of adaptive behavior SAB'02, Edinburgh, UK, August 2002, pp. 4857.

[12] T. Fukuda, Y. Kawauchi, and M. Buss, "Communication method of cellular robotics CEBOT as a selforganizing robotic system," in IEEE/RSJ International Workshop on Intelligent Robots and Systems, Tsukuba, Japan, September 1989.

[13] H. Kurokawa, A. Kamimura, E. Yoshida, K. Tomita, S. Murata, and S. Kokaji, "Self-reconfigurable modular robot (M-TRAN) and its motion design," in Seventh International Conference on Control, Automation, Robotics And Vision (ICARCV'02), Singapore, December 2002.

[14] H. H. Lund, R. Beck, and L. Dalgaard, "ATRON hardware modules for self-reconfigurable robotics," in Proceedings of the 10th International Symposium on Artificial Life and Robotics (AROB'10), Sugisaka and Takaga, Eds., Oita, Japan, 2005.

[15] B. Salemi, M. Moll, and W.-M. Shen, "SUPERBOT: A deployable, multi-functional, and modular self-reconfigurable robotic system," in Proc. IEEE International Conference on Intelligent Robots and Systems (IROS'06), Beijing, China, October 2006.

[16] D. G. Duff, M. Yim, and K. Roufas, "Evolution of polybot: A modular reconfigurable robot," in Proceedings, Harmonic Drive International Symposium, Nagano, Japan, 2001.

[17] A. Kamimura, H. Kurokawa, E. Yoshida, S. Murata, K. Tomita, and S. Kokaji, "Automatic locomotion design and experiments for a modular robotic system," in Transactions On Mechatronics, vol. 10, no. 3, June 2005.

[18] W.-M. Shen, B. Salemi, and P. Will, "Hormone-inspired adaptive communication and distributed control for conro self-reconfigurable robots," IEEE Transactions on Robotics and Automation, vol. 18, no. 5, pp. 700-712, October 2002.

[19] R. F. M. Garcia, K. Stoy, D. J. Christensen, and A. Lyder, "A self-reconfigurable communication network for modular robots," in Proceedings of the First International Conference on Robot Communication and Coordination (ROBOCOMM2007), October 2007.

[20] R. J. Tilley, Understanding Solids: The Science of Materials. John Wiley and Sons Ltd, 2004.

[21] D. Christensen, D. Brandt, U. Schultz, and K. Stoy, "Neighbor detection and crosstalk elimination in self-reconfigurable robots," in Proceedings of the First International Conference on Robot Communication and Coordination (ROBOCOMM2007), October 2007.

[22] T. I. Incorporated, "The RS-485 unit load and maximum number of bus connections," Analog Applications Journal, 2004-Q1. [Online]. Available: http://focus.ti.com/lit/an/slyt086/slyt086.pdf

[23] J. Vo, "A comparison of differential termination techniques," National Semiconductor, Application Notes, 1993. [Online]. Available: http://www.national.com/an/AN/AN-903.pdf

[24] Maxim/Dallas, "Guidelines for proper wiring of an rs-485 (tia/eia485-a) network," Application Notes, Jul. 2001. [Online]. Available: http://pdfserv.maxim-ic.com/en/an/AN763.pdf

[25] K. Stoy, "The deformatron robot: a biologically inspired homogeneous modular robot," Proceedings of the 2006 IEEE Conference on Robotics and Automation, pp. 2527-2531, May 2006.

[26] I. Boblan, R. Bannasch, H. Schwenk, F. Prietzel, L. Miertsch, and A. Schulz, "A human-like robot hand and arm with fluidic muscles: Biologically inspired construction and functionality." Embodied Artificial Intelligence, pp. 160-179, 2003. 